\title{
Proteção da biodiversidade em áreas privadas: um estudo de caso sobre trilhas clandestinas
}

Estratégias de conservação da biodiversidade no Brasil dependem das ações e usos em áreas privadas, que reúnem parte significativa da vegetação remanescente de nossos biomas. É um desafio, no entanto, definir estratégias eficazes para a proteção da biodiversidade nessas áreas, especialmente quando estas se encontram em zonas de amortecimento de Unidades de Conservação. Neste artigo exploramos um caso que representa este cenário - a realização de trilhas clandestinas na região de Paranapiacaba, em Santo André (SP), que dão acesso irregular ao Parque Estadual da Serra do Mar (PESM). São analisadas as ações tomadas para a gestão ambiental dessa problemática, bem como a percepção ambiental de gestores e trilheiros, a partir de um estudo de caso, com entrevistas, questionário e pesquisa documental e bibliográfica. Os resultados mostram que governo municipal, gestores do parque e proprietários das áreas tem focado seus esforços apenas em medidas de sinalização e fiscalização. Não há estudos sobre a viabilidade de se regularizar está trilha, e os visitantes não se sentem coibidos pelas ações tomadas. Este cenário atual é desfavorável para todos os atores e para a proteção da biodiversidade, uma vez que impactos ambientais têm se concretizado sobre esta área.

Palavras-chave: Gestão ambiental; Conservação ambiental; Conflito socioambiental.

\section{Protection of biodiversity in private areas: a case study on clandestine trails}

\begin{abstract}
Biodiversity conservation strategies in Brazil depend on actions and uses in private properties, which bring together a significant part of the remaining vegetation in our biomes. It is a challenge, however, to define effective strategies for the protection of biodiversity in these areas, especially when they are in buffer zones of Conservation Units. In this paper, we explore a case that represents this scenario - the realization of clandestine trails in the region of Paranapiacaba, in Santo André (SP), which give irregular access to the Serra do Mar State Park (PESM). The actions taken for the environmental management of this problem are analyzed, as well as the environmental perception of managers and trekkers, based on a case study, with interviews, questionnaire, and documentary and bibliographic research. The results show that the municipal government, park managers, and owners of the areas have focused their efforts only on signaling and inspection measures. There are no studies on the feasibility of regularizing this trail, and visitors do not feel restrained by the actions taken. This current scenario is unfavorable for all actors and for the protection of biodiversity since environmental impacts have materialized in this area.
\end{abstract}

Keywords: Environmental management; Environmental Conservation; Socio-environmental conflict.

Topic: Uso de Recursos Naturais

Reviewed anonymously in the process of blind peer.
Received: 09/08/2020

Approved: $25 / 09 / 2020$
Barbara Rodrigues Riccomini (D)

Universidade Federal de São Paulo, Brasil http://lattes.cnpq.br/9879248753160250 http://orcid.org/0000-0001-5789-0030

barbara.riccomini@outlook.com

Giovano Candiani (iD

Universidade Federal de São Paulo, Brasil http://lattes.cnpq.br/9950995765229751 http://orcid.org/0000-0001-9896-4390

giovanocandiani@gmail.com

Luciana Aparecida Farias

Universidade Federal de São Paulo, Brasil http://lattes.cnpq.br/3004797761865074 http://orcid.org/0000-0003-3343-3403

lufarias2@yahoo.com.br

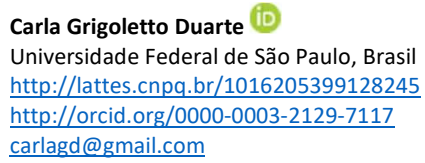

Carla Grigoletto Duarte (DD

Universidade Federal de São Paulo, Brasil http://lattes.cnpq.br/1016205399128245 http://orcid.org/0000-0003-2129-7117 carlagd@gmail.com

Referencing this:

RICCOMINI, B. R.; CANDIANI, G.; FARIAS, L. A.; DUARTE, C. G.. Proteção da biodiversidade em áreas privadas: um estudo de caso sobre trilhas clandestinas. Revista Ibero Americana de Ciências Ambientais, v.11, n.5, p.566-577, 2020. DOI: http://doi.org/10.6008/CBPC2179$\underline{6858.2020 .005 .0051}$ 


\section{INTRODUÇÃO}

Há no Brasil extensas áreas de vegetação natural não protegidas pela legislação ambiental. Unidade de Conservação (UC), Terra Indígena (TI), Áreas de Preservação Permanente (APP), Reserva Legal (RL) e outros instrumentos similares protegem apenas parte das áreas de vegetação natural brasileiras (MMA, 2017). Dados de Sparovek et al. (2011) indicam que 63\% do território brasileiro é ocupado por vegetação natural (537 milhões de hectares, Mha), e uma proporção significativa dessa área está situada em propriedades privadas. Dessa forma, estratégias de conservação da biodiversidade devem necessariamente incluir áreas privadas para que se amplie o potencial de conservação (MARQUES et al., 2012; PELLIN et al., 2009; LIMA et al., 2018).

No caso da Mata Atlântica, estimativas indicam que há 31 Mha de vegetação natural remanescente, sendo que apenas 3 Mha estão protegidos como UC de proteção integral ou TI, havendo grande proporção de áreas de vegetação natural situadas em terras privadas - cerca de 92\% (SPAROVEK et al., 2011). Sobre a área total do bioma, dados de 2017 indicam que de 110 Mha, há 9,1\% protegidos protegido como UCs ou TIs (EMBRAPA, 2020).

De acordo com a legislação brasileira, parte dessa vegetação em propriedades privadas fica protegida de forma obrigatória, como APP ou RL, de acordo com critérios da Lei de Proteção da Vegetação Nativa LPVN (Lei Federal no 12.651/2012). Outra parcela dessa vegetação pode ser protegida de forma voluntária, o que inclui a conversão de parte da propriedade em Reserva Particular do Patrimônio Natural (RPPN), seguindo a Lei do Sistema Nacional de Unidades de Conservação da Natureza - SNUC (Lei Federal no 9.985/200). Também é possível que a área seja direcionada para compensação de supressão de vegetação em áreas no mesmo bioma, como indica a Resolução SMA no 146/2017 no caso do estado de São Paulo. Na Mata Atlântica, de acordo com Guidotti et al. (2017), há 6,8 Mha de vegetação nativa desprotegida pela LPVN, mas que não necessariamente poderiam ser suprimidas, por estarem protegidas pela Lei da Mata Atlântica (Lei Federal no 11.428/2006). Áreas de vegetação nativa atualmente não protegidas por lei, usualmente se encontram em estágios sucessionais mais avançados, e têm grande relevância para ampliar a proteção da biodiversidade neste bioma já tão impactado. Em alguns casos, as pressões de uso nessas áreas são significativas, e a falta de instrumentos de proteção pode indicar que estas áreas não estão sendo geridas de forma a garantir condições adequadas para a manutenção da biodiversidade.

Uma das formas em que pode haver uso indevido é quando se estabelece a realização de trilhas clandestinas. A existência dessas trilhas pode levar ao estabelecimento do turismo desordenado, que pode trazer impactos adversos para a sustentabilidade local. Se a capacidade de carga da trilha não for respeitada, é esperado que ocorram impactos sobre a fauna relacionados ao ruído e à caça, sobre o solo, e também pode haver dispersão de resíduos sólidos pelo percurso; somam-se impactos sobre a economia local, uma vez que as trilhas regulares poderiam potencialmente receber mais visitantes e gerar dividendos para os monitores ambientais e UCs. Além disso, acidentes e visitantes perdidos na mata demandam o uso dos serviços de bombeiros e resgate, onerando serviços públicos. 
Neste artigo exploramos um caso que evidencia esse cenário - na região de Paranapiacaba, em Santo André (SP) propriedades privadas com presença de vegetação natural têm sido exploradas em trilhas clandestinas, dando acesso irregular ao Parque Estadual da Serra do Mar (PESM). São analisadas as ações tomadas para a gestão ambiental dessa problemática, bem como a percepção ambiental de gestores e trilheiros, a partir de um estudo de caso, com entrevistas, questionário e pesquisa documental e bibliográfica.

Na região de Paranapiacaba há um conjunto de áreas protegidas, e há iniciativas voltadas à compatibilização da conservação do patrimônio histórico e natural. Em nível municipal, há duas unidades de conservação de proteção integral: o Parque Natural Municipal Nascentes de Paranapiacaba (PNMNP) e a Reserva Biológica Alto da Serra de Paranapiacaba (RBASP). Paranapiacaba tem ainda parte de seu território na zona de amortecimento do PESM - Núcleo Itutinga-Pilões, e tem sua área como parte da Área de Proteção e Recuperação de Mananciais da Billings (Lei Estadual no13.579/2013). O Plano Diretor Municipal de Santo André define esta área como parte da Macrozona de Proteção Ambiental, que tem entre seus objetivos, garantir a produção de água e a proteção dos recursos naturais, recuperar áreas ambientalmente degradadas, e viabilizar o desenvolvimento econômico sustentável (SANTO ANDRÉ, 2012). Assim, há ampla provisão legal para a proteção dessas áreas, mas é preciso aprimorar sua execução.

\section{REVISÃO TEÓRICA}

\section{Conflitos ambientais em áreas protegidas}

O Brasil inicia os anos 20 do século XXI com conflitos ambientais contundentes. É um complexo quadro de ocupação e uso territorial, que envolve impactos sociais e ambientais severos e implicações econômicas significativas. A criação e gestão de áreas protegidas é um dos temas geradores de conflitos, uma vez que demanda, muito comumente, mudanças no uso e ocupação do solo dentro e no entorno da área delimitada.

Pesquisas sobre conflitos ambientais envolvendo áreas protegidas tanto enfatizam a necessidade de proteção dos ecossistemas e espécies (BENSUNSAN, 2006; DOUROJEANNI et al., 2007; TERBORGH et al., 2002), quanto a reflexão no sentido de exclusão social ou perspectiva de justiça social para os povos tradicionais que ocupavam e exploravam essas áreas (DIEGUES, 1994; GUHA, 2000; ALIER, 2012; PATTANAIK, 2007; SUASSUNA, 2007).

Neste contexto, Fleury et al. (2009) discutiram as representações sociais e conflitos ambientais no entorno do Parque Nacional das Emas em Goiás. As autoras relataram o conflito deflagrado, a partir do impasse acerca da zona de amortecimento no entorno do parque, envolvendo os produtores rurais e agentes vinculados a proteção ambiental do cerrado, o embate é representado pela definição do uso do espaço do entorno dessa unidade de conservação, de um lado tem-se a conservação ambiental e do outro, a produção agrícola direcionada ao mercado externo. As disputas são definidas pelas distintas representações de cada um dos atores e estas caracterizam-se como fenômenos complexos que se organizam como um saber acerca do real, reconhecendo que as representações são ao mesmo tempo geradas e adquiridas. As representações 
sociais carregam consigo as marcas das trajetórias, valores e interesses dos grupos sociais chamados a interagir acerca de um objeto comum, veiculando suas divergências (MOSCOVICI, 1978).

Para que conflitos e impactos na zona de amortecimento recebam maior atenção, é preciso que haja clareza quanto às causas e potenciais soluções para os problemas existentes. Dessa forma, é preciso realizar um planejamento adequado das ações a serem desenvolvidas, e prever adequadamente os recursos necessários (recursos humanos, infraestrutura e equipamentos) (WWF, 2012).

Além disso, garantir que o planejamento e a condução do processo foram adequados é essencial para a efetividade da gestão. A gestão das ações em zonas de amortecimento depende da cooperação entre atores. É preciso que os municípios alinhem seu planejamento territorial ao zoneamento previsto no plano de manejo das unidades de conservação (LIMA et al., 2018). A compatibilidade entre os zoneamentos é fundamental para a efetividade da proteção da biodiversidade, assim como é essencial que os gestores de UCs e gestores municipais trabalhem de forma conjunta, para que, uma vez que as normas estejam alinhadas, que seja viabilizado o cumprimento do que foi disposto.

\section{METODOLOGIA}

Esta pesquisa qualitativa foi estruturada como um estudo de caso, que se caracteriza por ser uma estratégia de investigação na qual se explora profundamente um fenômeno, casos, relacionados pelo tempo e atividade, sendo adotada mais de um procedimento de coleta de dados (CRESWELL, 2010).

A pesquisa incluiu revisão da literatura técnica e cientifica, pesquisa documental, realização de entrevistas e aplicação de questionários. A pesquisa bibliográfica foi realizada por meio das seguintes bases indexadas: Scientific Eletronic Library Online (Scielo), Scopus, e a base da Coordenação de Aperfeiçoamento Pessoal de Nível Superior (Capes). Também foram utilizados periódicos, livros, dissertações e teses. Na pesquisa documental, foram analisados planos de manejo, atlas municipal/estadual, Plano Diretor do Município de Santo André, além de site da Prefeitura do Município de Santo André, site do Governo do Estado de São Paulo em relação as unidades de conservação, assim como sites das empresas que atuam nas propriedades privadas da área de estudo. Essa etapa teve como objetivo compreender aspectos da gestão ambiental e de conflitos relacionados a unidades de conservação e proteção da biodiversidade, bem como identificar o histórico de ações de gestão ambiental na área de estudo.

Foram elaborados roteiros de entrevistas, com o objetivo de identificar as visões dos diferentes atores sociais envolvidos na gestão ambiental da área de estudo. As entrevistas foram realizadas com representantes do setor público, incluindo funcionários e ex-funcionários da Prefeitura do Município de Santo André (5 entrevistados), gestores do PNMNP (2 entrevistados), PESM (1 entrevistado do Núcleo Itutinga-Pilões) e RBASP (1 entrevistado), e com representantes do setor privado, reunindo proprietários ou representantes das áreas privadas em que são realizadas as trilhas clandestinas (2 entrevistados). As entrevistas foram agendadas e realizadas pessoalmente com os gestores, funcionários e ex-funcionários públicos, assim como os proprietários das áreas privadas. Essas entrevistas ocorreram entre agosto de 2017 e março de 2018. 
Já os questionários foram direcionados ao público que frequenta ou já fez as trilhas clandestinas em estudo. $\mathrm{O}$ questionário foi disponibilizado de forma online e divulgado em redes sociais, em grupos e em fóruns onde se discute sobre trilhas no Estado de São Paulo. O questionário ficou disponível de novembro de 2017 até agosto de 2018 tendo sido respondido por 57 visitantes autodeclarados. Foi utilizada a metodologia de análise de conteúdo, para identificar, analisar e discutir os conteúdos das entrevistas e questionários aplicados (BARDIN, 2016).

\section{Caracterização da área de estudo}

Há diversas trilhas clandestinas na região de Paranapiacaba (Figura 1). $\mathrm{O}$ acesso a essas trilhas ocorre por diversas entradas, sendo que a trilha mais conhecida da região é denominada como 'Trilha da Ferradura', conforme indicado na Figura 2. Ela se inicia e finaliza por dois acessos da rodovia SP-122 e tem como destino a Cachoeira da Fumaça, localizada no PESM, um dos principais locais acessado pelos visitantes. O percurso totaliza aproximadamente $7 \mathrm{~km}$.

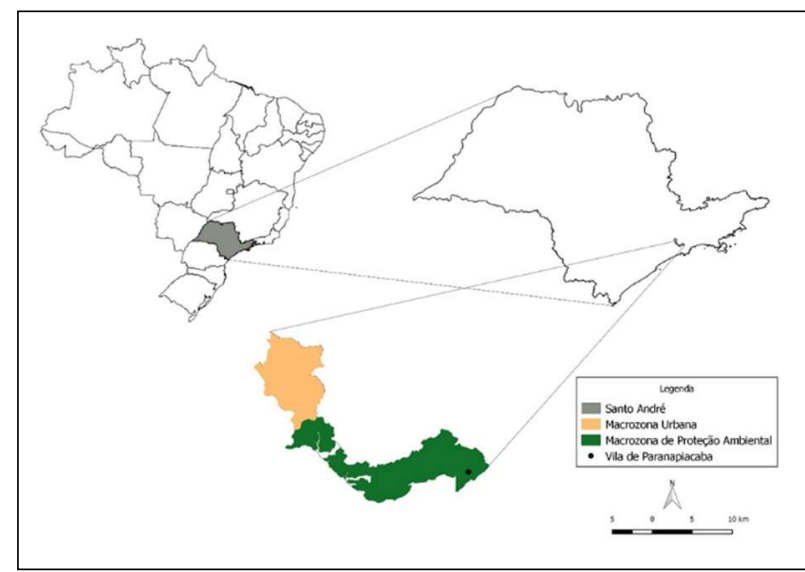

Figura 1: Vila de Paranapiacaba, no município de Santo André/SP.

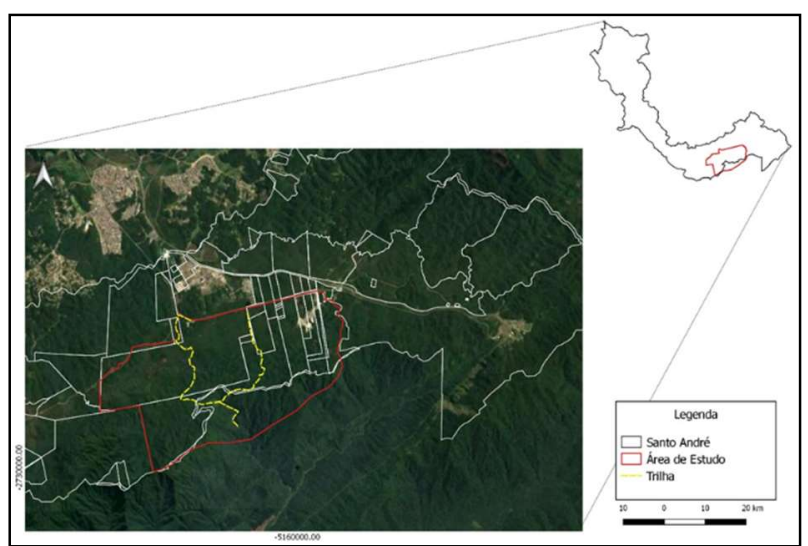

Figura 2: Traçado da trilha da ferradura, na Região de Paranapiacaba, Santo André/SP.

Conforme o Plano Diretor Municipal de Santo André, apresentado na Figura 3, está trilha está localizada na Macrozona de Proteção Ambiental, quase em sua totalidade na Zona de Conservação Ambiental, que tem como objetivo promover a manutenção da qualidade ambiental e conservar os recursos naturais; uma pequena parcela (trecho à nordeste) é parte da Zona de Desenvolvimento Econômico Compatível, que tem como objetivo oferecer áreas para o desenvolvimento econômico local, com atividades econômicas de baixo impacto ambiental, que sejam compatíveis com as atividades de turismo ambiental e conservação dos mananciais.

Ao sul da área de estudo, está situado o Parque Estadual da Serra do Mar (PESM), que foi criado em 1977 pelo governo do Estado de São Paulo e atualmente é administrado pela Fundação Florestal. O parque abriga um dos maiores remanescentes de Mata Atlântica, com uma extensão de 332 mil hectares, compreendendo cerca de 25 municípios entre o sul do estado de São Paulo e a divisa do estado do Rio de Janeiro. Devido à sua grande extensão o parque foi dividido em núcleos administrativos. Como mencionado, a Cachoeira da Fumaça acessada por meio da trilha irregular em estudo, fica no PESM, Núcleo Itutinga-Pilões 
(INSTITUTO FLORESTAL, 2006), e a trilha em si, é parte da zona de amortecimento do PESM.

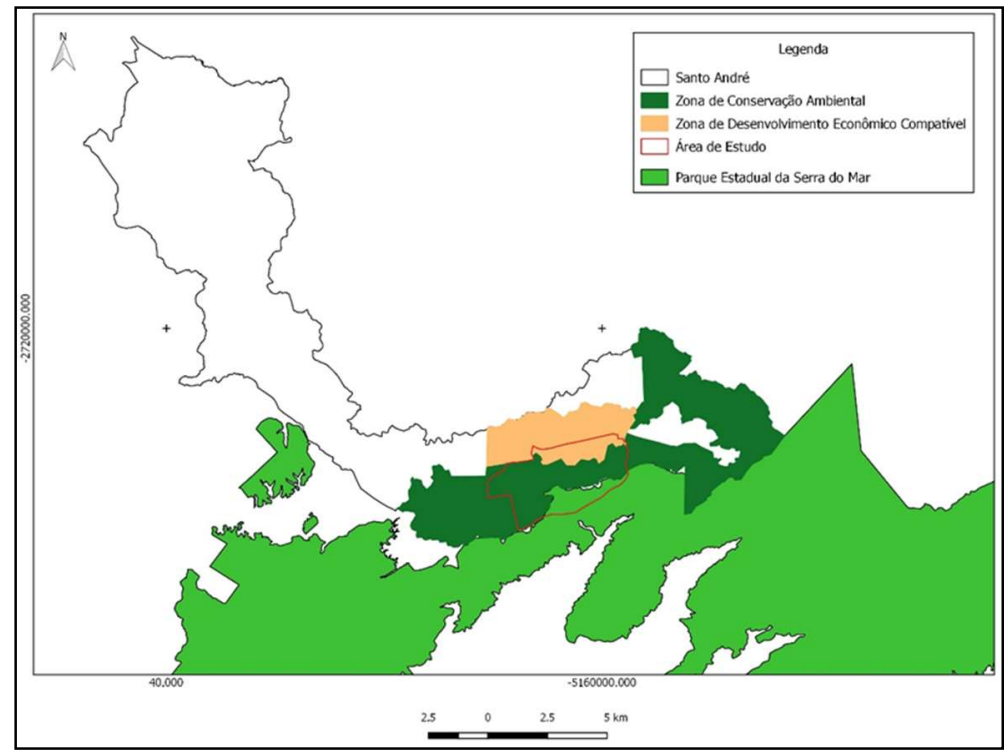

Figura 3: Zoneamento Ambiental, na Região de Paranapiacaba, Santo André/SP.

As propriedades privadas pelas quais a trilha passa incluem lotes de pessoas físicas e jurídicas. No que remete pessoas jurídicas, havia uma empresa de logística, que encerrou suas atividades no local, mas criou em 2017 uma RPPN em parte da sua propriedade; e há uma indústria química, que está na região desde 1941, e que ocupa parte da propriedade com as instalações industriais e deixa outra parte do território sem uso ou ocupação industrial. Os lotes em nome de pessoas físicas são áreas sem exploração econômica, encontram-se abandonados.

\section{RESULTADOS E DISCUSSÃO}

\section{Ações de gestão voltadas ao ecoturismo na região de Paranapiacaba}

A Vila de Paranapiacaba foi arquitetada em função da construção da São Paulo Railway, a estrada de ferro que ligou o porto de Santos ao Planalto Paulista, em 1850. Com arquitetura de herança europeia, a Vila teve um papel importante na história do transporte de cargas e passageiros no estado de São Paulo. Visando assumir a administração da Vila, a prefeitura de Santo André criou, em 2001, a Subprefeitura de Paranapiacaba e Parque Andreense, e em 2002 formalizou a compra da Vila de Paranapiacaba que antes estava sob administração da Rede Ferroviária Federal S.A. - RFFSA.

A ação de criação da Subprefeitura ocorreu pouco depois da elaboração da Política Municipal de Gestão e Saneamento Ambiental, que organizou o sistema de gestão ambiental municipal e proveu instrumentos para atuação na recuperação e manutenção da qualidade ambiental, avançando também na busca pela integração entre a ação municipal e os sistemas de gestão de recursos hídricos e do planejamento urbano em contexto metropolitano (DUARTE et al., 2012; SANTO ANDRÉ, 1998).

Entre 2001 a 2008, a Subprefeitura conduziu o Programa de Desenvolvimento Local Sustentável, que visava integrar políticas públicas nas áreas de turismo, preservação do patrimônio cultural, planejamento urbano, conservação ambiental, desenvolvimento social, participação cidadã e gestão administrativo- 
financeira (FIGUEIREDO et al., 2014). Porém, em 2009 está Subprefeitura foi extinta, criando-se a Secretaria de Gestão de Recursos Naturais de Paranapiacaba e Parque Andreense.

O turismo foi fortalecido para transformar a realidade local. Para isso, houve então investimentos em ferramentas para impulsionar o turismo, como gastronomia local, festivais e ecoturismo em trilhas fomentadas principalmente com a criação do Parque Natural Municipal Nascentes de Paranapiacaba em 2003 (PMSA, 2011). Figueiredo et al. (2014) destacaram que este programa foi inovador ao promover a integração de diferentes temas da gestão pública, a descentralização e a participação da sociedade. De acordo com os autores, o Programa trouxe desenvolvimento político, econômico e social para a Vila.

Áreas vizinhas do entorno da Vila de Paranapiacaba, no entanto, ficaram à mercê do turismo predatório, pois são áreas com potencial turístico e não foram todas incluídas no Programa de Desenvolvimento Local Sustentável. Há atrativos naturais, especialmente cachoeiras, e, com isso, atividades clandestinas como acampamentos e trilhas irregulares foram se intensificando na região. Uma operação em 2016 coibiu o acesso clandestino de mais de 2.500 pessoas nas trilhas do Parque Natural Nascentes de Paranapiacaba, Parque Estadual da Serra do Mar e zona de amortecimento nos arredores da Rodovia Adib Chamas; emitiu ainda 32 autos de infração ambiental e apreendeu 27 barracas e acessórios de camping (PMSA, 2016).

O acesso irregular a essas áreas traz problemas de degradação ambiental (com destaque para a deposição de resíduos sólidos ao longo da trilha e intensificação de processos erosivos), há riscos para a segurança dos visitantes (quedas, afogamentos), e há crime de invasão de propriedade (PMSA, 2016). Há ainda impactos desconhecidos sobre a fauna e a flora, uma vez que não há estudos sobre a capacidade de carga da trilha, nem controle da quantidade de pessoas e frequência de acesso.

A principal ação para coibir as trilhas irregulares ao longo do tempo foi a fiscalização, realizada pela prefeitura em parceria com outros órgãos - recentemente tem sido realizada pelo Departamento de Meio Ambiente da Secretaria de Gestão de Recursos Naturais de Paranapiacaba e Parque Andreense, com o apoio do Departamento da Guarda Municipal, do Parque Estadual da Serra do Mar (Núcleo Itutinga-Pilões) e a Polícia Militar Ambiental (PMSA, 2016).

A fiscalização é direcionada para o sujeito conflitante, no caso, os visitantes, havendo poucos esforços direcionados aos proprietários das áreas privadas que não estão zelando pelo território. Em 2017, uma reforma administrativa na prefeitura de Santo André, criou a Secretaria de Meio Ambiente (2018 a 2020), que inclui, entre outros, o Departamento de Gestão de Paranapiacaba e Parque Andreense, e o Departamento de Parques Municipais. Também ficaram vinculados a esta Secretaria, o Conselho Municipal dos Representantes de Paranapiacaba e Parque Andreense e o Fundo de Gestão do Patrimônio Histórico e Arquitetônico de Paranapiacaba e Parque Andreense (SANTO ANDRÉ, 2012).

Quanto à proteção legal da área, a trilha em análise tem seu trajeto passando por áreas protegidas por instrumentos que podem ser menos ou mais restritivos. A área da cachoeira da fumaça está dentro do PESM, uma UC de proteção integral que no zoneamento de seu Plano de Manejo classifica a área como de recuperação ambiental, não prevendo uso turístico. 
A trilha percorre propriedades privadas na zona de amortecimento do PESM, que não possuem uso econômico ativo por parte dos proprietários atualmente. A área onde se dá o percurso da trilha está inserido na zona de amortecimento do Parque, majoritariamente na Zona de Conservação Ambiental de acordo com o Plano Diretor Municipal de Santo André, área em que ações devem ser tomadas para manutenção da qualidade ambiental, incluindo a restrição de atividades que causem impactos ambientais adversos. A trilha em estudo tem sido explorada de forma irregular, sem estudos que possam garantir observância da capacidade suporte da trilha ou segurança para os usuários.

\section{Percepção dos visitantes da trilha}

A compreensão do conflito existente também passa pelo entendimento do sujeito conflitante, no caso, os visitantes que realizam as trilhas irregulares. Os questionários aplicados com este público-alvo buscaram entender o perfil desses visitantes. Os resultados apontam que 63,5\% eram do sexo masculino, a idade variava de 18 a 33 anos, a escolaridade incluiu ensino médio completo (28,8\%), ensino médio incompleto $(30,8 \%)$ e ensino superior completo $(34,6 \%)$. A renda mensal de $46,2 \%$ variou de um a três salários-mínimos; a renda de 26,9\%, de três a seis salários mínimos; de 15,4\%, até um salário-mínimo e 7,7\% não possuíam renda.

Sobre a relação com as trilhas da região, os resultados mostram que $82,7 \%$ dos entrevistados diziam já ter realizado as trilhas clandestinas da região mais que uma vez. A maioria conheceu essas trilhas por conhecidos/amigos $(65,4 \%)$ ou redes sociais $(21,2 \%)$. Essas trilhas foram realizadas com grupos de amigos em $67,3 \%$ dos casos, e $25 \%$ responderam que foram com grupo de amigos e com um guia. Vale ressaltar que não existem profissionais regulamentados para guiar nessas áreas, pois são trilhas irregulares.

A motivação para realizar tais atividades estava relacionada ao contato com a natureza para $51,9 \%$, e $28,8 \%$ se motivam por aventura. Os resultados dos questionários aplicados aos visitantes que frequentam a região apontam, ainda, que $86,5 \%$ dos visitantes declaram que continuariam fazendo essas trilhas mesmo sabendo que a trilha é irregular e cientes que há fiscalização na área.

Os dados desse questionário demonstram que existe um público majoritariamente jovem interessado pelo ecoturismo nessa região, com potencial para ajudar a movimentar renda para a fomentação do ecoturismo. Relatos dos visitantes indicam, ainda, que no percurso da trilha há presença de resíduos sólidos espalhado e a ocorrência de processos erosivos.

\section{Percepção dos gestores responsáveis pela área}

Os proprietários entrevistados neste estudo declararam que tem conhecimento sobre essas trilhas irregulares. Alguns declararam que tentam coibir a entrada desses indivíduos colocando placas informando que os territórios são propriedades privadas; porém, estas são removidas pelos indivíduos que continuam adentrando o local.

Sobre a fiscalização, foi questionado junto aos gestores da prefeitura de Santo André, o motivo pelo qual as ações eram direcionadas aos visitantes, e porque não acionar judicialmente os proprietários daquelas 
áreas para que eles zelem pelo território. Para o representante da empresa proprietária de uma das áreas privadas, 'a prefeitura não autuou a empresa porque a gente tenta trabalhar em parceria com a prefeitura, para tentar coibir esse tipo de acesso'.

Os gestores municipais também relataram que a fiscalização, 'resolve uma parte, não soluciona, mas resolve uma grande parcela do problema'. 'Você precisa ter políticas de desenvolvimento sustentável que envolvam a população em práticas econômicas que sejam compatíveis com essa região'. Para os gestores do PESM, a fiscalização 'não é suficiente porque o parque é enorme, a gente tem que cuidar de 43,8 mil hectares'.

Sobre possíveis soluções para a gestão do problema da trilha em estudo, na entrevista com responsável pela indústria química, foi relatado que:

Tem que montar um projeto, dizer quanto ele custa e submeter à análise da diretoria (...) a empresa participará? Eu não sei te dizer, eu acho que sim, tendo em vista que parte do terreno é nosso, tendo em vista que a gente também tem interesse de preservar a região e tudo mais, eu acho que a chance é muito grande de conseguir seguir adiante. $O$ que pode acontecer é esse projeto custar muito caro e a empresa falar, olha eu não posso investir, vamos achar outros parceiros para tentar investir, existem várias maneiras de viabilizar isso.

O problema permeia o município (Santo André) e o estado (PESM) e nesta transição entre esferas políticas, a prefeitura relata que o PESM deveria tomar a frente deste problema, em entrevista é relatado que: 'um outro problema que enfrentamos é em relação ao PESM, porque essa área é toda área de amortecimento do Parque Estadual da Serra do Mar. O PESM deveria tomar a frente disso e a prefeitura toma por conta da degradação'. Já o representante do PESM entende que: 'o município deve tomar essas providências'.

O que se observa nas falas dos gestores é que são tomadas ações restritas à coibição da presença dos visitantes, que se resumem a placas de sinalização afixadas pelos proprietários, e fiscalização voltada aos visitantes por parte da prefeitura. Não há diálogo ou ações conjuntas voltadas ao estudo da regularização da trilha. As falas vão na contramão da responsabilidade compartilhada entre os órgãos que atuam na região.

No caso em análise, é possível identificar que há alinhamento entre as normas (Plano de Manejo e Plano Diretor), no entanto, seu cumprimento está comprometido. A fiscalização, como já é de amplo conhecimento acerca de instrumento de comando e controle, não é medida suficiente para impedir os trilheiros de explorar a região de forma irregular.

Para Gonçalves et al. (2011), a gestão em UCs é ineficiente em muitos casos, e indicam que consideram como desafio a implantação do Plano de Manejo e atuação do conselho gestor, que na prática não atendem aos objetivos que deveriam cumprir. Esses dois desafios afetam diretamente a gestão em zonas de amortecimento, que extrapolam a esfera de ação de uma UC, mas são indispensáveis entre estratégias de conservação da área.

O Plano de Manejo do PESM considera o potencial de cooperação entre as entidades vizinhas, como a prefeitura de Santo André, por meio de articulações de políticas e colaboração em programas de conservação e ecoturismo (INSTITUTO FLORESTAL, 2006). No entanto, as entrevistas mostram que não houve menção a qualquer articulação para que se estudasse a possibilidade de regularização das trilhas da região. 
O tratamento de um conflito deve iniciar com um protagonista que articule ações junto com os outros atores envolvidos. No caso da Trilha da Ferradura, certamente seria necessário realizar um estudo quanto à viabilidade de se regularizar esse traçado e as visitas à Cachoeira da Fumaça.

Essa opção precisa ser articulada com o PESM Núcleo Itutinga-Pilões, uma vez que, no zoneamento estabelecido no Plano de Manejo, as áreas visitadas são classificadas como Zona de Recuperação, área com ecossistema degradado que deve ser recuperado para promover a conservação e futuramente ser incorporada em zonas permanentes da unidade. Seria preciso avaliar se estas áreas poderiam ser convertidas em Zona de Uso Extensivo, que tem como objetivo de manejo a proteção das áreas naturais gerando o menor impacto antrópico, mesmo oferecendo acesso ao público por meio de trilhas a atrativos naturais (INSTITUTO FLORESTAL, 2006).

Caso fosse viável a regularização desta trilha, poderia ser articulada a proteção das áreas de vegetação nativa nas propriedades privadas por meio da criação de RPPNs, para então organizar a oferta de monitoria e de serviços de apoio aos visitantes. A alternativa do ecoturismo em áreas privadas pode ser inspirada em outros projetos. No caso do Parque das Neblinas, situado nos municípios de Mogi das Cruzes e Bertioga, São Paulo, pertencente à empresa Suzano Papel e Celulose, e que é caracterizado como reserva particular, com área de 6 mil hectares, nos quais 518 hectares são RPPN. O Parque promove a conservação da natureza atrelado à pesquisa científica, educação socioambiental e ecoturismo (INSTITUTO ECOFUTURO, 2018). Já o Legado das Águas é a maior reserva privada da Mata Atlântica, com 31 mil hectares localizados no Vale do Ribeira, de propriedade da Votorantim. Há atividades de ecoturismo, ações para o desenvolvimento territorial, pesquisa e inovação.

Em Paranapiacaba, sendo possível, a regularização das trilhas reforça a vocação dessa região para o ecoturismo, que poderá contribuir para o fortalecimento de ações de educação ambiental e conservação de áreas protegidas. Como mencionamos anteriormente, pesquisas sobre conflitos ambientais envolvendo áreas protegidas tanto enfatizam a necessidade de proteção dos ecossistemas e espécies quanto a reflexão no sentido de exclusão social ou perspectiva de justiça social para comunidades que dependem da exploração dessas áreas para sua subsistência. A solução no ecoturismo é, potencialmente, um caminho que pode aliar as duas visões existentes sobre conflitos ambientais em unidades de conservação.

Trabalhar com conflitos consiste em transformá-los, considerando diretrizes que: reconheçam o problema e suas causas, bem como os interesses e argumentos das partes envolvidas; ter claro os posicionamentos distintos; ter o diálogo como princípio indissociável do processo; gerar processos que resultem em ideias e alternativas; promover a avaliação coletiva das alternativas criadas, a partir de critérios definidos e aceitos pelos atores sociais; realizar negociação das bases que assegurem o cumprimento do que for acordado; realizar ações planejadas, reconhecendo o esforço das partes e estabelecendo os métodos de avaliação e monitoramento do processo (ALVARADO, 2003).

A legislação implica que a conservação é o principal desafio a ser promovido nessa região, e necessariamente deve se dar de forma colaborativa entre os atores envolvidos. Em propriedades localizadas em zonas de amortecimento, o exercício de atividades econômicas é condicionado ao bem-estar social 
(VITALLI et al., 2009), de forma que convém a responsabilidade compartilhada neste território e destes problemas socioambientais.

\section{CONCLUSÕES}

Neste estudo foram exploradas as ações de gestão relacionadas à ocorrência de trilhas irregulares em Paranapiacaba, Santo André, e a percepção dos atores envolvidos nessa problemática. A Trilha da Ferradura explorada neste artigo tem seu trajeto passando por propriedades privadas na zona de amortecimento do PESM, e que dão acesso clandestino a uma cachoeira dentro do PESM.

Constatou-se que o conflito estabelecido na região, parte da desarticulação entre os atores governamentais envolvidos. Não há estudos sobre a viabilidade de se regularizar está trilha, e os visitantes não se sentem coibidos pela fiscalização. Certamente, depender apenas da fiscalização e de sinalização nas áreas pode resultar em impactos sobre fauna, flora, solo, e sobre a segurança dos trilheiros.

A proteção da biodiversidade depende de ações executadas em áreas privadas, e no caso das zonas de amortecimento, sempre será necessário diálogo entre proprietários, gestão municipal e gestão da UC. Ações efetivas sobre esta e outras trilhas clandestinas da região poderão contribuir para o fortalecimento do ecoturismo em Paranapiacaba, valorizando ainda mais sua importância histórica e ambiental.

\section{REFERÊNCIAS}

ALIER, J. M.. O ecologismo dos pobres: conflitos ambientais e linguagens de valoração. 2 ed. São Paulo: Contexto, 2012.

ALVARADO, M. E. F.. Los conflictos y las formas alternativas de resolución. Rede de Revistas Científicas de América Latina, el Caribe, España y Portugal, p.265-278, 2003.

BARDIN, L.. Análise de conteúdo. São Paulo: 70, 2016.

BENSUNSAN, N.. Conservação da biodiversidade em áreas protegidas. Rio de Janeiro: FGV, 2006.

CRESWELL, J. W.. Projetos de Pesquisa: método qualitativo, quantitativo e misto. Porto Alegre: Artmed, 2010.

DIEGUES, A. C. S.. O mito moderno da natureza intocada. São Paulo, HUCITEC, 1994.

DOUROJEANNI, M. J.; PÁDUA, M. T. J.. Biodiversidade: a hora decisiva. Curitiba: UFPR, 2007.

DUARTE, C. G.; MALHEIROS, T. F.. Habitação e Gestão Ambiental em Áreas de Mananciais: o caso do Município de Santo André (SP). Saúde e Sociedade, v.21, n.3, p.82-95, 2012.

EMBRAPA. Empresa Brasileira de Pesquisa Agropecuária. Atribuição das Terras do Brasil. Campinas: Embrapa, 2017.

FIGUEIREDO, V. G. B.; CAETANO, J. R. G.. Os desafios da descentralização e a gestão do desenvolvimento local sustentável. In: FIGUEIREDO, V. G. B.; SILVA, R. R..

Paranapiacaba: um patrimônio para a humanidade. São Paulo: Marquise, 2014. p.256.
FLEURY, L. C.; ALMEIDA, J. P.. A conservação ambiental como critério de relações entre grupos e valores: representações e conflitos no entorno do parque Nacional das Emas, Goiás. Ambiente \& Sociedade, v.12, n.2, p.357-372, 2009.

GONÇALVES, M. P.; BRANQUINHO, F. T. B.; FELZENSZWALB, I.. Uma análise contextual do funcionamento efetivo e participação popular em uma unidade de conservação: o caso da Área de Proteção Ambiental de Petrópolis (Rio de Janeiro: Brasil). Sociedade \& Natureza, Uberlândia, v.2, n.23, p.323-334, 2011.

GUHA, R.. The paradox of global environmentalism. Environmentalism Current History, v.99, n.640, 2000.

GUIDOTTI, V; FREITAS, F. L. M.; SPAROVEK, G.; PINTO, L. F. G.; HAMAMURA, C.; CARVALHO, T.; CERIGNONI, F.. Números detalhados do novo Código Florestal e suas implicações para o PRAs. Sustentabilidade em Debate, v.5, p.1-10, 2017.

INSTITUTO ECOFUTURO. Parque das Neblinas. Eco futuro, 2018.

INSTITUTO FLORESTAL. Plano de Manejo do Parque Estadual da Serra do Mar. São Paulo: Secretaria de Estado do Meio Ambiente, 2006.

LIMA, E. A. C.; RANIERI, V. E. L.. Land use planning around protected areas: Case studies in four state parks in the Atlantic forest region of southeastern Brazil. Land Use Policy, v.71, p.453-458, 2018.

MARQUES, E. M.; RANIERI, V. E. L.. Determinantes da decisão de manter áreas protegidas em terras privadas: 0 caso das Reservas Legais do Estado de São Paulo. Ambiente 
e Sociedade, v.15, n.1, p.131-145, 2012.

MMA. Ministério do Meio Ambiente. Planaveg: Plano Nacional de Recuperação da Vegetação Nativa. Brasília: Ministério do Meio Ambiente, 2017.

MOSCOVICI, S.. A representação social da psicanálise. Rio de Janeiro: Zahar, 1978.

PATTANAIK, S.. Conservation of environment and protection of marginalized fishing communities of lake Chilika in Orissa, India. Journal Hum. Ecol., v.22, n.4, 2007.

PELLIN, A.; RANIERI, V. E. L.. Motivações para o estabelecimento de RPPNs e análise dos incentivos para sua criação e gestão no Mato Grosso do Sul. Natureza \& Conservação, v.7, n.2, p.72-81, 2009

PMSA. Prefeitura Municipal de Santo André. Fiscalização coíbe trilhas clandestinas em Paranapiacaba. Santo André: Prefeitura Municipal de Santo André, 2016.

PMSA. Prefeitura Municipal de Santo André. Plano de manejo do Parque Natural Municipal Nascentes de Paranapiacaba. Santo André: Instituto Ekos, 2011.

SANTO ANDRÉ. Lei n. 7.733 de 14 de outubro de 1998. Política Municipal de Gestão e Saneamento Ambiental, Santo André, 1998.
SANTO ANDRÉ. Lei n. 9.394, de $\mathbf{5}$ de janeiro de 2012. Altera a lei $n .8 .696$ de 17 de dezembro de 2004, que institui o Plano Diretor do Município de Santo André. Santo André, 2012.

SNUC. Sistema Nacional de Unidades de Conservação. Lei n. 9.985, de 18 de julho de 2000. Brasília: SNUC, 2000.

SPAROVEK, G.; BARRETTO, A.; KLUG, I.; PAPP, L.; LINO, J.. A revisão do Código Florestal brasileiro. Novos Estud. CEBRAP, n.89, p.111-135, 2011.

SUASSUNA, D.. Um olhar sobre políticas ambientais: Projeto TAMAR. Brasília: Thesaurus, 2007.

TERBORGH, J.; SCHAIL, C.; DAVENPORT, L.; RAO, M. Tornando os parques eficientes: estratégias para a conservação da natureza nos trópicos. Curitiba: UFPR, 2002.

VITALLI, P. D. L.; ZAKIA, M. J. B.; DURIGAN, G.. Considerações sobre a legislação correlata à zona-tampão de unidades de conservação no Brasil. Ambiente \& sociedade, v.12, p.67-82, 2009.

WWF. World Wide Fund for Nature. Efetividade da gestão das Unidades de Conservação federais do Brasil: resultados de 2010. WWF, 2012.

A CBPC - Companhia Brasileira de Produção Científica (CNPJ: 11.221.422/0001-03) detém os direitos materiais desta publicação. Os direitos referem-se à publicação do trabalho em qualquer parte do mundo, incluindo os direitos às renovações, expansões e disseminações da contribuição, bem como outros direitos subsidiários. Todos os trabalhos publicados eletronicamente poderão posteriormente ser publicados em coletâneas impressas sob coordenação da Sustenere Publishing, da Companhia Brasileira de Produção Científica e seus parceiros autorizados. Os (as) autores (as) preservam os direitos autorais, mas não têm permissão para a publicação da contribuição em outro meio, impresso ou digital, em português ou em tradução. 